\title{
Effects of Para-Chlorophenylalanine Upon Brain Stimulated Affective Attack in the Cat
}

\author{
R. J. KATZ \\ Mental Health Research Institute, University of Michigan, Ann Arbor MI 48109 \\ and \\ E. THOMAS \\ Department of Psychology, Bryn Mawr College, Bryn Mawr PA 19010
}

(Received 20 October 1975)

\begin{abstract}
KATZ, R. J. AND E. THOMAS. Effects of para-chlorophenylalanine upon brain stimulated affective attack in the cat. PHARMAC. BIOCHEM. BEHAV. 5(4) 391-394, 1976. - Previous investigations of the effects of parachlorophenylalanine (PCPA) on affective attack have produced equivocal results. The present report examined the effects of PCPA upon attack elicited by electrical stimulation of the ventromedial hypothalamic nucleus in the cat. Using a within-animals design and postdrug testing clear potentiation of affective attack patterns was observed for a number of the components of attack behavior (approach, use of forepaws, and biting). The present results may point to possible serotonergic involvement in the inhibitory control of several aspects of affective attack.
\end{abstract}

Affective attack Aggression Brain stimulation PCPA Rage Serotonin Ventromedial hypothalamus

MUCH evidence, largely based upon the centrally active tryptophan hydroxylase inhibitor para-chlorophenylalanine (PCPA); [4, 14, 20], points to the existence of a serotonergic inhibitory mechanism in the control of predatory behavior $[5,8,12,16,22]$. Despite this consistent pattern of disinhibition for predatory aggressive behavior, however, only partially consistent results are seen after equivalent biochemical manipulations on a second type of aggression, affective attack (rage); $[8,18]$. Thus, although early reports suggest increases in irritability and aggressiveness subsequent to the administration PCPA $[8,14,22]$ other more recent reports fail to obtain any such increases $[3,16,28]$, or alternately, report decreased aggressiveness [7].

Because brain stimulated emotional behavior offers specific, quantifiable, and stable measures of aggression which are readily elicitable under controlled current conditions it represents a useful baseline for the further evaluation of the effects of serotonergic depletion upon affective attack. The present report sought to clarify the effects of PCPA upon affective aggressive behavior, using direct stimulation of the central attack substrate to establish a baseline for the evaluation of drug effects. All testing was carried out using a within-animals design and extensive testing of the component behaviors that comprise an attack episode.
METHOD

\section{Animals}

Animals were four adult female cats weighing 2.0-3.5 $\mathrm{kg}$, obtained from a local supplier (Bio-Medical Supply Inc.). All animals were maintained on ad lib food and water throughout the experiment. Normal day-night cycles of 14 hr daylight $/ 10 \mathrm{hr}$ darkness were maintained by natural and artificial lighting.

Surgery

Animals were anesthetized with an intraperitoneal injection of $35 \mathrm{mg} / \mathrm{kg}$ sodium pentobarbital (Nembutal). Each animal was stereotaxically implanted with 12 stainless steel electrodes $0.25 \mathrm{~mm}$ in diameter insulated to the tip. Two indifferent electrodes were attached to stainless steel screws in the skull for purposes of monopolar stimulation. All the electrodes were aimed at the ventromedial hypothalamic nucleus [23]. Surgery was performed under aseptic conditions, and at the end of surgery 150,000 units of Bicillin were administered intramuscularly.

\section{Apparatus}

During testing the subjects were maintained in a $61 \times$ $61 \times 61 \mathrm{~cm}$ isolation chamber, with a constant level of

\footnotetext{
${ }^{1}$ This research was supported by Grants MH 07417 and MH 15946 from the National Institute of Mental Health to the respective authors Both authors are grateful to Mr. Peter Bauer for his considerable assistance in the running of the reported investigation.
} 
masking noise provided by a ventilating fan and white noise generator. One wall of the chamber consisted of a one-way mirror, through which all observations were made.

\section{Procedure}

One week after surgery animals were tested for responding to stimulation. Electrical pulses were generated by a Grass SD-9 stimulator and monitored across a 100 ohm resistor in a series with the animal on a HewlettParkard 122A oscilloscope. Stimulation consisted of monophasic square waves (200 pulses/sec) delivered for $1.0 \mathrm{msec}$ duration through a $2 \mu \mathrm{F}$ capacitor in series with the animal to produce biphasic pulses and minimize electrode polarization. All stimulation was presented unilaterally in $15 \mathrm{sec}$ trains with a 1 min interval between trains. Current levels were determined immediately prior to each stimulation by the presentation of a single $1.0 \mathrm{msec}$ pulse. Only sites that consistently yielded attack characterized by vocalization (hissing and growling), piloerection, and directed attack were chosen for additional testing. During this initial screening and all subsequent aggression testing a small stuffed toy animal manipulated by means of a manually operated rod was maintained in constant irregular motion during the test session and served as an attack object for the assessment of the various components of attack behavior.

Attack behavior was quantified in two manners: first by the determination of the stimulation threshold for attack and response probability at threshold; and secondly by means of a rating procedure for the effects of the drug on various components of attack to a constant suprathreshold stimulus.

Thresholds were obtained by starting with a clearly noneffective stimulus and incrementing the current on each trial by $0.1 \mathrm{~mA}$ until an attack was obtained. Behavior in response to suprathreshold stimulation was broken down into three categories defined as: (1) approach (locomotion followed by paw or mouth contact with the attack object); (2) biting; and, (3) use of forepaws. Each category was rated on a $0-3$ scale by two independent raters, one of whom was the experimenter and the second of whom was blind with regard to drug administration, current level, and the purpose of the experiment.

The criteria established for scaling each category were as follows:

Approach. 0- no observable locomotion, 1 - delayed locomotion terminating in mouth or paw contact prior to or at of fset of stimulation, 2 -- short latency initiation of locomotion $(2-5 \mathrm{sec})$ and direct approach to attack object, 3 immediate $(<2 \mathrm{sec})$ locomotion and direct approach to attack object.

Biting. $0 \cdots$ no oral contact with attack object, 1 - any oral contact with attack object involving jaw movement, 2 - one or more clearly defined bites, with full opening and closure of mouth, 3 -.. repeated rhythmic biting with full jaw opening and closure.

Use of Forepaws. 0 -. no paw contact with attack object, 1 - any paw contact with attack object, 2 - at least one paw in contact with attack object for more than $2 \mathrm{sec}$ with attempts to hold attack object, 3 - both paws in extended contact with attack object. The particular categories and scaling procedures have previously been shown to be effective in the analysis of drug effects upon attack $[13]$.
Two stages of testing were employed. There were: establishment of a stable baseline of aggressive behavior under nondrugged conditions, and drug administration for two consecutive days, with behavioral testing for drug effects beginning immediately prior to the second day of drug injection. All test sessions were less than $1 \mathrm{hr}$ in length, and separated from each other by $24 \mathrm{hr}$.

Initial (baseline) testing consisted of $2-4$ sessions of testing subsequent to the initial behavioral protocol. Testing was continued until measures of threshold, approach, and biting responses of a given animal were unchanged for two consecutive sessions; no animal required more than 4 sessions. In order to equate number of injections for all animals all control sessions were run without injections of any sort.

Immediately after the final day of baseline testing, all animals were injected with PCPA and behavioral testing was resumed $24 \mathrm{hr}$ later. A second injection of PCPA was administered immediately after Day 1 drug testing (i.e., 48 $\mathrm{hr}$ after the final baseline) and testing continued for an additional three sessions.

Para-chorophenylalanine methyl ester (Sigma C-3635) was prepared in a normal saline vehicle solution to which 1 drop of polyoxyethylene mono-oleate (Tween-80; Sigma P1754) had been added for purposes of solvation. The drug was injected intrapertoneally $(250 \mathrm{mg} / \mathrm{kg})$ in approximately $5 \mathrm{cc}$ vehicle solution. The dosage used was based upon previous reports indicating approximately $80 \%$ depletion of whole brain serotonin levels in the cat under similar procedures $[4,11,20]$.

\section{Statistics}

In order to assess drug effects across extended testing each response was analyzed across the testing period via a repeated measures analysis of variance [6]. In addition, correlations between experimenter and blind rater were calculated using Pearson's r [6] .

\section{Histology}

At the close of the experiment each animal was injected with an overdose of Nembutal, and perfused first with a solution of normal saline and subsequently with a solution of $10 \%$ formaldehyde in saline. Brains were removed, sliced in 40 micron sections, stained and examined microscopically [23]. All sites which were used were located in the ventromedial hypothalamic nucleus and in the posterior hypothalamic area [24].

\section{RESULTS}

Between rater correlation for all behavioral data was 0.85. All data are presented as means of ratings of the two raters. Results are presented in Table 1 . It may be seen that PCPA produced slight but not significant decreases in evocation threshold during tests conducted after initiating drug administration. It may also be seen that probability of response increased significantly, as did two of the three behavioral response category ratings (approach and use of paws). The third response category (biting) was also increased but not significantly. Thus, all measures of attack showed evidence of potentiation, with three of five measures reaching statistical significance.

\section{DISCUSSION}

Previous reports have produced only partially consis- 
TABLE 1

EFFECTS OF PCPA UPON BRAIN STIMULATED AFFECTIVE BEHAVIOR

\begin{tabular}{|c|c|c|c|c|c|c|c|}
\hline $\begin{array}{l}\text { Response } \\
\text { Category }\end{array}$ & $\begin{array}{l}\text { Mean Rating }{ }^{\dagger} \\
\text { (predrug) }\end{array}$ & $\begin{array}{l}\text { Mean Rating } \dagger \\
\text { (postdrug } \\
\text { Day 1) }\end{array}$ & $\begin{array}{l}\text { (Postdrug } \\
\text { Day 2) }\end{array}$ & $\begin{array}{l}\text { (Postdrug } \\
\text { Day 3) }\end{array}$ & $\begin{array}{l}\text { (Postdrug } \\
\text { Day 4) }\end{array}$ & $\mathbf{F}$ & $p^{*}$ \\
\hline $\begin{array}{l}\text { Threshold } \\
\text { (in milliamperes) }\end{array}$ & 0.49 & 0.50 & 0.40 & 0.40 & 0.43 & 3.1 & $<.10$ \\
\hline $\begin{array}{l}\text { Probability } \\
\text { (at pre-drug } \\
\text { threshold) }\end{array}$ & 0.31 & 0.50 & 0.75 & 0.87 & 0.87 & 4.5 & $<.025$ \\
\hline Approach & 1.25 & 1.50 & 1.75 & 2.25 & 2.00 & 3.8 & $<.05$ \\
\hline Biting & 1.00 & 1.00 & 1.50 & 2.00 & 2.00 & 3.2 & $<.06$ \\
\hline Use of Forepaws & 1.0 & 1.25 & 1.50 & 2.00 & 1.75 & 3.3 & $<.05$ \\
\hline
\end{tabular}

*Degrees of freedom are 4,12 for all categories.

$\dashv$ PCPA was administered at the close of this session.

tent evidence for PCPA disinhibition of affective attack. The present results suggest that PCPA does in fact potentiate a variety of attack behaviors, and that it additionally increases the overall probability of affective attack. In contrast to previous reports which generally employed baselines of shock induced and spontaneous aggression in rats and mice for the assessment of altered affective behavior, the present report employed both a novel species and a novel model of attack. While the use of central stimulation to directly activate attack circuits might be objected to as being less appropriate than a variety of more naturalistic means of producing attack (e.g., via shock or other peripheral irritation) it should be noted that the present model of attack shares both behavioral [9] and motivational [1] properties in common with the latter. Moreover, 5-HT depletion has previously been shown to augment peripheral irritability in a manner consistent with the present results $[15,22]$.

Two additional points might be noted regarding the biochemical and behavioral specificity of the present manipulations. Since a within-animals design was employed direct biochemical assessment of PCPA induced changes in brain amines was necessarily precluded. While PCPA is relatively specific inhibitor of tryptophan-hydroxylase, at least some evidence suggests it may also deplete catecholamine (CA) containing neurons $[14,17,19,25]$. However, the involvement of catecholamines in the present results may be questioned in terms of the established involvement of CA in aggressive behavior. Reis [21] reports that both noradrenaline (NA) and dopamine (DA) may be facilitatory neurotransmitters in affective attack. Since
PCPA might have partially depleted NA and DA, a reduction rather than an increase in aggression could be predicted ceteris paribus. Since the present results point to an increase in aggressivity, NA and DA may play only a minor role in the present results.

It might also be objected that the present increases in aggression may reflect an effect of the testing procedure itself, independent of drugs. Although a within-animals design again precluded a definitive answer to this question, several factors argue against this interpretation. We have had occasion to subject undrugged subjects to a schedule of stimulation quite similar to the one reported herein. Animals receiving 5 daily stimulation sessions of $1 \mathrm{hr}$ each showed either small decreases in responding ( 3 of 5 animals) or no change ( 2 of 5 animals) ( $F$ ratios for attack evocation threshold, attack probability, approach, biting and use of forepaws were $0.8,1.2,0.9,0.7,1.3$ respectively, $d f=$ 4,16 ). These results differ considerably from the reported PCPA effects. Other published reports also suggest decreases in sensitivity with repeated testing [10].

In conclusion, it might be noted with regard to the present findings that recent reports suggest an increased for spontaneous intraspecific attack in mice with lower serotonin turnover [27]. While there exist both theoretical [18] and empirical [2] grounds for dissociating this model of attack from the one employed in the present design, these findings taken in conjunction with reports of PCPA facilitated predation $[5,8,12,1619]$ suggest that a reduction in the turnover of serotonin, whether due to biochemical intervention or lower metabloic capacity will cause increases in several forms of aggression.

\section{REFERENCES}

1. Cohen, B. C., G. W. Brown and M. C. Brown. Avoidance learning motivated by hypothalamic stimulation. $J$. exp. Psychol. 53: 228-233, 1957.

2. Creer, T. Effects of previous housing conditions on shock induced aggression. J. exp. Analysis Behav. 23: 451-456, 1975.

3. Conner, R. L., J. M. Stolk, J. D. Barchas, W. C. Dement and S. Levine. The effect of para-chlorophenylalanine upon shock induced fighting behavior in rats. Physiol. Behav. 5: $1221-1224,1970$.

4. Delorme, F., J. Froment et M. Jouvet. Suppression du sommeil par la parachloromethaphetamine et la parachlorophenylalanine. C.r. Soc. Biol. 160: 2347-2350, 1966.
5. DiChiara, G., R. Gamba and P. F. Spano. Evidence for inhibition by brain serotonin of mouse killing behavior in rats. Nature, Lond. 233: 272-273, 1971.

6. Dixon, W. J. and F. J. Massey. Introduction to Statistical Analysis. New York: McGraw Hill, 1969.

7. Dominguez, M. and V. G. Longo. Taming effect of parachlorophenylalanine on septal rats. Physiol. Behav. 4: 1031-1033, 1969.

8. Ferguson, J., S. Henriksen, H. Cohen, G. Mitchell, J. Barchas and $W$. Dement. Hypersexuality and behavioral changes in cats caused by administration of p-chlorophenylalanine. Science 168: $499-501,1970$. 
9. Flynn, J. P. The neural basis of aggression in cats. In; Neurophysiology and Emotion, edited by D. C. Glass. New York: Rockefeller University Press, 1967.

10. Hutchison, R. R. and J. W. Renfrew. Stalking at tack and eating behaviors elicited from the same sites in the hypothalamus. $J$. comp. physiol. Psychol. 61: 360-367, 1966.

11. Jalfre, M., M. A. Roch-Monachon and W. Haefely. Methods for assessing the interactions of abents with 5 hydroxytryptamine neurons and receptors in the brain. In: Serotonin New Vistas: Advances in Biochemical Psychopharmacology, edited by $\mathrm{E}$. Costa, G. L. Gessa and M. Sandler, Vol. 10, New York: Raven Press, 1974, p. $121-133$.

12. Karli, P., M. Vergnes, and F. Didiergeorges. Rat mouse interspecific behavior and its manipulation by brain ablation and brain stimulation. In: Biology of Aggressive Behavior, edited by S. Garattini and E. Sigg, New York, 1969, p. 47.

13. Katz, R. and E. Thomas. Effects of scopolamine and a-methylparatyrosine upon predatory attack in cats. Psychopharmacologia 42: 153-157, 1974

14. Koe, B. K. and A. Weissman. P-chlorophenylalanine: a specific depleter of brain serotonin. J. Pharmac. exp. Ther. 154: $499-516,1966$.

15. Lints, C. and H. E. Dent. Induced reversal of brain damage in the rat. Physiol. Behav. 4: 29-31, 1969.

16. McLain III, W. C., B. T. Cole, R. Schreiber and D. A. Powell: Central catechol and indole systems and aggression. Pharmac. Biochem. Behav. 2: 123-126, 1974.

17. Miller, F., R. H. Cox Jr., W. R. Snodgrass and R. P. Maikel. Comparative effect of p-chlorophenylalanine, p-chloroamphetamine, and p-chloromethyl amphetamine on rat brain norepinephrine serotonin and 5-hydroxyindole -3 -acetic acid. Biochem. Pharmac. 21: 435-442, 1970.

18. Moyer, K. E. Types of aggression and their physiological basis. Communs Behav. Biol. (A) 2: 65, 1968.
19. Peters, D. A. V., M. Filezewski and I. M Mazurkiewicz-Kwilecki. Effects of p-chlorophenylalanine upon catecholamine synthesis in rat brain, heart and adrenals. Biochem. Pharmac. 21: 2282-2284, 1972.

20. Pujol, J. F., A. Buguet, J. Froment, B. Jones and M. Jouvet. The central metabolism of serotonin in the cat during insomnia: a neurophysiological and biochemical study after the administration of p-chlorophenylalanine or destruction of the Raphe system. Brain Res. 29: 195-212 (1972).

21. Reis, D. J. The chemical coding of aggression in brain. In: Neurohumoral Coding of Brain Function: Advances in Behavioral Biology, Vol. 10, edited by R. D. Myers and R. R. Drucker-Conlin. New York: Plenum, 1974, p. 125-151.

22. Sheard, $M$. $H$. The effect of $p$-chlorophenylalanine on behavior in rats: relation to brain serotonin and 5-hydroxyindolacetic acid. Brain Res. 15: 524-528, 1969.

23. Skinner, J. E. Neuroscience: A Laboratory Manual. Philadelphia: Saunders, 1971.

24. Snider, R. S. and W. T. Neimer. A Stereotaxic Atlas of the Cat Brain. Chicago: University of Chicago Press, 1964.

25. Tanaka, C., Y. A. Yoh and S. Takaori. Relationship between brain monoamine levels and Sidman Avoidance in rats treated with tyrosine and tryptophan hydroxylase inhibitors. Brain Res. 45: 153-164, 1972.

26. Tenen, S. The effects of P-chlorophenylalanine, a serotonin depletion on avoidance acquisition, paw sensitivity and related behavior in the rat. Psychopharmacologia 10: 204-219, 1961 .

27. Valzelli, L. 5-Hydroxytryptamine in Aggressiveness. In: Serotonin: New Vistas, Advances in Biochemical Psychopharmacology. Vol. 11. edited by G. L. Gessa, and M. Sandler. New York: Raven Press, 1974, pp. 255-265.

28. Zitrin, A., F. A. Beach, J. D. Barchas and W. C. Dement: Sexual Behavior of cats after administration of parachlorophenylalanine. Science 170: 868-879, 1970. 